\title{
A recepção de Nietzsche a partir do Index da biblioteca do Seminário Central de São Leopoldo/ RS
}

\author{
Adilson Felicio Feiler*
}

\begin{abstract}
Resumo: O Index da biblioteca do Seminário Central Nossa Senhora da Conceição em São Leopoldo, no Rio Grande do Sul guardou grande parte da obra filosófica que, nos anos que antecederam ao Concílio Vaticano II, esteve grandemente sob suspeita. Dentre este arsenal de obras, se destaca toda a obra de Nietzsche, da qual se ocupa este texto. Por mais paradoxal que pareça, Nietzsche, apesar da maneira controvertida com que tratava sobre temas como a cultura, a moral, o Cristianismo, Nietzsche, encontrou, no Seminário Central, diversos leitores. Estes, atraídos pela beleza de seu estilo e pela maneira impetuosa com que encarrava os problemas de sua época, levaram o pensamento de Nietzsche, em grande medida, a sério. Pode-se inferir a hipótese de que a recepção do pensamento de Nietzsche no Seminário Central foi se configurando, de certa forma, como ferramenta para se pensar os destinos futuros da Igreja Institucional.
\end{abstract}

Palavras-chave: Nietzsche - recepção - index - cristianismo.

* Professor do Programa de Pós-Gradução em Filosofia da Universidade do Vale do Rio dos Sinos, São Leopoldo, Brasil.

Correio eletrônico: afeiler@unisinos.br 
Feiler, A. F.

\section{Introdução}

Quem passasse através de uma porta enorme, do segundo pavimento da ala leste do Seminário Central de São Leopoldo/RS ${ }^{1}$ deparar-se-ia com um dos maiores acervos bibliográficos da América do Sul, no séc. XIX². Se deparava também, nesta biblioteca, em certo local, com uma inscrição que encimava uma pequena porta ao fundo, à esquerda: Index Librorum Prohibitorum. O ingresso por esta porta era permitido a apenas três pessoas: o Reitor do Seminário, o Bibliotecário e o seu Assistente. Não raro este era um espaço que alimentava o imaginário e a curiosidade de muitos que frequentavam a biblioteca.

Neste pequeno espaço, também vulgarmente denominado de "Inferno", estava depositado um acervo de livros considerados contrários aos ensinamentos da Igreja Católica. O Index Librorum Prohibitorum ou Index Expurgatorius, entidade criada em 1559 pela Sagrada Congregação da Inquisição da Igreja Católica Romana. A lista incluía, em nosso caso, autores literários como Rabelais (obra completa) ou La Fontaine (Contes et Nouvelles), pensadores como Descartes e Montesquieu, e científicos como Conrad Gessner e Copérnico. Este último entrou na lista como consequência do processo de Inquisição contra Galileu, por um decreto da Congregação da Fé, que obrigava expurgar certas passagens incompatíveis com a fé, que confirmavam que a terra não era o centro do sistema solar e, sim, o sol

1 O Seminário Central de São Leopoldo foi criado em 03 de outubro de 1869, contava inicialmente com 12 alunos. Inicialmente era chamado de Seminário Provincial, pois atendia apenas aos seminaristas do Estado do Rio Grande do Sul. Em 1934, quando passa a atender aos seminaristas de todo o Brasil, somando um total de 164 alunos, passa a se chamar Seminário Central. O Seminário Central teve o seu auge no ano de 1952, quando contou com 325 alunos (Andriotti, 1946, p. 87). Com o fechamento do Seminário Central em 1960 a sua biblioteca foi transferida para o Memorial Jesuíta que é abrigado pela Biblioteca da Universidade do Vale do Rio dos Sinos (Unisinos) em São Leopoldo.

2 Como atesta uma pesquisa sobre as atividades dos jesuítas no Sul do Brasil "Aqui, encontrava-se, como ainda se encontra, uma biblioteca aparelhada e um acervo de revistas de fazer inveja a muitas instituições" (Bohnen, 1989, p. 247).

238 | Cad. Nietzsche, Guarulhos/Porto Seguro, v.38, n.3, p. 237-258, setembro/dezembro, 2017. 
(teoria heliocêntrica). Johannes Kleper, como muitos outros, também foram incluídos na lista por defender o heliocentrismo. A $32^{\mathrm{a}}$ edição do Index, publicada em 1948, continha aproximadamente 4.000 títulos censurados por diversas razões; heresia, deficiência moral, sexo explícito, entre outras. Incluía também, junto a uma parte da lista histórica, boa parte dos novelistas do século XIX, como Zola, Balzac e Victor Hugo. Entre os pensadores se encontram Descartes, Pascal, Spinoza, David Hume, Kant, Berkeley, Condorcet e Bentham. Autores notáveis como Comte, Schopenhauer, Marx e Nietzsche, devido a seus ateísmos e hostilidades com a Igreja católica, eram nomes certos a cada edição da lista. As Cartas Anuas, publicadas em um anuário da Companhia de Jesus, datado de outubro de 1898 a outubro de 1899, fala sobre um caminho filosófico a ser oferecido à juventude brasileira, e, por isso, de antemão apresentava o que devia ser evitado.

Apesar de serem muitas as obras de diferentes autores presentes no Index da Biblioteca do Seminário Central Nossa Senhora da Conceição, o que nos interessa neste artigo são os textos e referências a Nietzsche, já que é um estudo da recepção de Nietzsche no Brasil. Dos livros de Nietzsche, presentes no Index da Biblioteca do Seminário Central, temos notícia apenas de uma edição alemã de Assim Falava Zarathustra de $1899^{3}$. Porém, fora do Index, há inúmeras referências indiretas a Nietzsche com posições as mais diversas, algumas com tons de reprovação ao autor e outras tecendo elogios a diversos aspectos de seu pensamento. É justamente essa posição diferenciada e até antagônica que se depreende de comentários sobre Nietzsche que vão ser destacados em nossa pesquisa. Analisar a diversidade destes comentários é o que procuraremos realizar no decorrer destas páginas.

Ao adentrarmos na pesquisa como tal, fazemos algumas considerações sobre o vocábulo recepção. Este é derivado do verbo latino recipio, is,-ere, receptum, é um verbo transitivo que significa

3 NIETZSCHE, Also Sprach Zarathustra, 1899. (Acervo 3C-Col.O.R. e Especiais. Registro I.21-15). 
Feiler, A. F.

aceitar, admitir, receber, acolher. Deste verbo se deriva o substantivo feminino receptio-onis, que significa aceitação, admissão, acolhida recepção. Dada essa gama de significados, torna-se difícil avaliar em que medida o termo recepção é o mais adequado para aplicar a maneira pela qual o pensamento de Nietzsche foi introduzido no Seminário Central Nossa Senhora da Imaculada Conceição porque não foi sem alguma hostilidade que este pensamento atravessou os umbrais do Seminário. Contudo, como veremos no decorrer deste artigo, ao mesmo também se manifestaram gestos positivos. Um dos aspectos mais instigantes desta pesquisa é o da variedade de posições frente ao pensamento de Nietzsche. Avaliaremos esta diversidade partindo de uma reflexão sobre autores que inspiraram a recepção de Nietzsche, seguindo sua recepção em manuais utilizados nas classes do Seminário, e, por fim, a sua recepção em outros escritos, ditos e expressões.

\section{Autores que influenciaram a recepção de Nietzsche}

Antes de discorrermos sobre os vários autores que deixaram escritos sobre Nietzsche, consideramos importante trazer referências às fontes nietzschianas e a autores estrangeiros que, direta ou indiretamente, influenciaram em sua recepção. Como se tratava de uma instituição jesuíta, voltada à formação de líderes religiosos, era bastante marcante, neste trabalho de recepção, o elemento de crítica ao Cristianismo que se depreendia da obra de Nietzsche. Por essa razão, os professores tiveram sempre o cuidado de trabalhar os diversos autores a partir de suas fontes originais. No caso de Nietzsche, como já citado na Introdução, um volume de Assim falava Zarathustra, em alemão, é o texto de que temos notícia. Contudo, pelas citações nos diversos trabalhos sobre Nietzsche, é possível perceber que as referências ao autor se davam a partir de textos como: A Gaia Ciência, A genealogia da moral, Além do bem e do mal e Ecce homo.

$240 \mid$ Cad. Nietzsche, Guarulhos/Porto Seguro, v.38, n.3, p. 237-258, setembro/dezembro, 2017. 
Tratar de um autor como Nietzsche em um ambiente eminentemente religioso tem sido um problema, por isso, vale lembrar que Nietzsche passou a ser uma ferramenta para responder a algumas questões que se depreendiam da própria vivência do Cristianismo da época. Dado que o alvo das críticas de Nietzsche era o Cristianismo Ocidental de herança platônica, a instrumentalização do filósofo alemão se dava justamente para descontruir um tipo de experiência cristã baseada na aposta de um tipo de autoridade moral ideal e dualista. O Cristianismo Oriental, de fato, não se rendeu à herança platônica. Há, nesta tradição cristã, uma concepção de totalidade e plenitude, o que o faz respirar serenidade. Talvez seja este aspecto cândido, terno e sereno, vivido por Dostoiévski em seu ambiente cristão oriental, que tenha impressionado a Nietzsche.

A herança platônica é um traço exclusivo do Cristianismo Ocidental, presente desde o fomento da oposição: Deus x ser humano, céu x terra, até em concepções morais como as prescrições dietéticas, o encorajamento da prática de jejuns e abstinências, bem como a afirmação de uma esfera ideal centralizadora que se exprime, através de status de dogma, a inerrância do papa pelo Decreto do Concílio Vaticano I (1869) denominado Infalibilidade Pontifícia. Este Concílio foi motivado como reação às descobertas realizadas no campo da ciência, mostrando uma maneira de a autoridade eclesiástica rivalizar com as autoridades científicas. Evidente que as decisões desse Concílio tenham provocado reações diversas. Não foram apenas movimentos de aceitação, o que era de esperar para aquela época, mas também uma série de manifestações contrárias a tais decisões, que se seguirão até os anos de 1961, com o Concílio Vaticano II, com um acento muito menor na dimensão institucional, e uma maior flexibilização no que tange aos aspectos dogmáticos. É aqui que Nietzsche tem ocupado, progressivamente, um papel importante, pois ajudou a se ter uma visão muito mais crítica quanto à maneira pela qual se concebem os dogmas e as verdades de fé, bem como todo o 
Feiler, A. F.

aparato institucional. Não tardaram a aparecer inúmeros fragmentos dentro de capítulos de livros, artigos e comentários sobre aspectos para os quais o pensamento de Nietzsche poderia ajudar a trazer luzes. Em um manual de Filosofia Moral, de 1914, adotado para o terceiro ano do curso de Filosofia do Seminário Central, denominado Philosophia Moralis, escrito pelo jesuíta suíço Pe. Victore Cathrein (1845-1931) lemos: "Secundum Nietzsche doctrina moralis vigens est propria manciporum et perperam per christianismum principatum obtinuit, homines eminentes versantur trans bonum et malum. ${ }^{94} \mathrm{E}$ segue em uma edição posterior deste manual: "Secundum Nietzsche doctrina moralis vigens fraude introducta est in favorem miserorum ideoque iterum abolenda. ${ }^{\circ 5} \mathrm{O}$ Professor Cathrein, referindo-se a Nietzsche, sublinha este aspecto de sua crítica à moral como um problema introduzido por um uso indevido do Cristianismo. Logo, conclui o professor, seguindo Nietzsche, por ser isso uma doutrina introduzida pelo Cristianismo para sorte dos infelizes, dever ser abolida. Já na época da publicação deste manual, havia clareza quanto ao alvo principal das críticas de Nietzsche ao Cristianismo: a moral.

$\mathrm{O}$ manual acima aludido inspirou a maneira de ensinar Nietzsche por parte dos jesuítas que foram professores de filosofia do Seminário Central. Como é sabido, todos eles eram europeus, provenientes da Alemanha, Suíça e Áustria. Por essa razão, muitos dos livros e manuais eram trazidos com eles de seu país de proveniência, como é o caso do manual de Éthica Philosophica, de autoria do Pe. Jakobus Gemmel, SJ. Este manual inspirou, inclusive, a forma pela qual as teses eram expostas, com uma tese central (Thesis), a divisão da tese (Divisio Thesis), a argumentação ou a explicitação da tese (Argumentatio) que se subdividia em forma de sentenças (Sententiae)

4 "Segundo Nietzsche a doutrina moral vigente é própria da emancipação e supremacia obtida falsamente pelo Cristianismo, e os homens versados e iminentes estão além do bem e do mal". (Cathrein, 1907, p. 59).

5 "Segundo Nietzsche a doutrina moral vigente é uma fraude introduzida para a sorte dos infelizes e deve ser abolida". (Cathrein, 1914, p. 75).

242 | Cad. Nietzsche, Guarulhos/Porto Seguro, v.38, n.3, p. 237-258, setembro/dezembro, 2017. 
e outros filósofos e correntes filosóficas (Alii Philosophi). Neste ponto é que entravam modelos filosóficos como os de Nietzsche. Acrescentava-se, ainda, a confirmação da tese (Confirmatio) e, por fim, suas objeções (Objectiones). Pe. Gemmel diz neste manual, sobre a filosofia de Nietzsche, que "Nietzsche falso intellescerat Platonem et Aristotelem. ${ }^{6 "}$ Por essa razão, pela compreensão que se tinha destes dois filósofos, base do pensamento ocidental, a conclusão a que se pode chegar é a de que quaisquer que sejam as linhas de seu pensamento, serão postas sob suspeita. Gemmel acusa Nietzsche de relativista e de sofista, criticando-o por ter operado uma verdadeira inversão de valores, ao elevar os que são fortes e impiedosos e rebaixar os que são fracos, pobres e compassivos. Gemmel constata, ainda, que em Nietzsche os homens biologicamente avantajados se inspiram na força biológica dos gregos, em cuja moralidade não há espaço para debilidades. Ao passo que a raiz da pobreza, da debilidade e da invalidez se encontra no Cristianismo, o grande responsável pela "falsificaverunt tabulas valorem." Diante disso, Nietzsche aponta para a urgência de uma "(...) nova revolutio valorum" que para Gemmel é um "(...) genuinum statum antichistianum" Percebemos que Gemmel possui uma leitura bastante crítica de Nietzsche, o que pode ter influenciado de maneira decisiva sobre a recepção de seu pensamento no Seminário Central, que compreendia tanto a maneira de ensinar a sua filosofia, bem como a sua produção. Contudo, apesar de toda a sua criticidade, não deixa de enfatizar aspectos importantes de seu pensamento, como aquele que diz respeito ao fim da vida humana, o tornar-se aquilo que se é, como um movimento da mais pura autenticidade de vida e pensamento. "Nietzsche circa vitae finem scribit (Also Sprach Zaratustra, Aug, Kröner, 418): 'Sein bin

\footnotetext{
6 "Nietzsche compreendeu falsamente Platão e Aristóteles". (Gemmel, 1931, p. 118).

7 “(...) falsificaram as tábuas de valores” (Ibidem, p. 119).

8 “(...) nova revolução dos valores. (Ibidem).

9 “(...) genuína atitude anticristã”. (Ibidem).
} 
Feiler, A. F.

ich ob ich in der Frevler Rotte auch bis zur Stunde bin geblieben... (...) Ich will sich kennen, Unbekannter, du tief in meinen Seele greifenden... (...) Ich will dich kennen, selbest dir dienen" ${ }^{10}$ Estes versos, citados do alemão, como parte do poema intitulado Ao Deus desconhecido, o Pe. Gemmel, assim como tantos outros que se têm apropriado deste, muitas vezes, mesmo que indevidamente, têm a intenção de tentar mostrar em Nietzsche uma veia espiritual, seu desejo de conhecer a Deus; um conhecimento que restaurasse as forças da vida. Nesta mesma linha da afirmação da vida, Gemmel acentua o papel da supremacia do super-homem, como provindo de uma natureza humana desordenada e violenta. Isto deixa entender, claramente, sua vinculação ao pensamento nacional socialista, marca que perdurará um bom espaço de tempo, o que levantará ainda mais a suspeita sobre o pensamento de Nietzsche. Pelos dois manuais acima expostos percebemos que Nietzsche foi um autor que marcou profundamente, despertando posições diversas e até antagônicas, também no Seminário Central de São Leopoldo.

\section{A recepção de Nietzsche nos manuais de aula}

Catherein e Gemmel, embora não representem a recepção de Nietzsche no Brasil, certamente influenciaram autores que escreveram e ensinaram sobre Nietzsche. Estes foram justamente apresentados no início por serem aqueles que plantaram as bases das duas grandes vertentes que a recepção de Nietzsche foi adquirindo nos anos sucessivos no Seminário Central: os que levaram a sério a leitura de Nietzsche, pensando-o como uma ferramenta, ainda que não a única, importante para a crítica e os que o rejeitaram como uma figura negativa, falsa, e até caricata.

10 "Eu sou teu, embora até o presente me tenha associado aos sacrílegos... (...) Quero te conhecer, ó Desconhecido, tu me penetras a alma... Quero te conhecer e a ti servir". Esta citação o Pe. Gemmel faz de partes de um poema de Nietzsche intitulado Ao Deus Desconhecido.

244 | Cad. Nietzsche, Guarulhos/Porto Seguro, v.38, n.3, p. 237-258, setembro/dezembro, 2017. 
Endossa aquela primeira vertente a posição de Armindo Trevisan, que diz "Nietzsche talvez tivesse razão ao exclamar: 'Os cristãos devem apresentar-me um rosto mais próprio de remidos e entoar-me canções mais famosas se pretendem que eu creia no redentor deles." "11 Trevisan segue a ideia de que o Cristianismo pode incorrer no perigo de forjar pessoas entristecidas, incapazes de se alegrarem. Se a grande boa notícia que pregam não conduz à alegria então há um problema. Segue, igualmente, esta linha de pensamento um especialista em Kierkegaard, o jesuíta, Pe. Antonio Steffen (1906-1993), professor de Filosofia do Seminário Central, e “(...) primeiro doutor em Filosofia nascido no Rio Grande do Sul ${ }^{12}$. Steffen, comentando Kierkegaard, cita Nietzsche:

A sua fundamentação subjetivística da fé envolve uma tendência, que não só se opõe ao catolicismo mas também ao protestantismo e em última análise se afasta de todo o cristianismo. E aqui talvez ocorra a lembrança de Nietzsche. Concluo pois comparando a posição deste espírito hostil a toda a religião com a de Kierkegaard, alma essencialmente religiosa. É comum a ambos a angústia frente à materialização e decadência da humanidade. Ambos veem a causa dessa decadência na falta de compreensão para interesses superiores e na incapacidade para o esforço e a renúncia a serviço deles. ${ }^{13}$

A partir desta citação vemos que há uma leitura de Nietzsche muito mais otimista, ou seja, menos caricata e mais atenta a determinados problemas colocados pelo autor, como é o caso da decadência cultural e do cristianismo institucional. A publicação deste livro se deu no ano de 1958, período em que já se preparava toda uma discussão que viria a culminar no Concílio Vaticano II. O interessante é perceber em que medida a leitura de autores como Kierkegaard e Nietzsche vem trazer luzes para uma revisão da caminhada do Cristianismo institucional.

11 Trevisan, 1946, p. 95

12 Leite, 2005, p. 171

13 Steffen, 1958, pp. 55-56

Cad. Nietzsche, Guarulhos/Porto Seguro, v.38, n.3, p. 237-258, setembro/dezembro, 2017. 
Feiler, A. F.

O professor Steffen, assim como outros professores do Seminário Central, conseguiu identificar o problema central nas críticas de Nietzsche ao Cristianismo e sua chamada de atenção à conversão a uma prática de vida cristã, tornando-o autêntico. Sobre esse ponto o Professor Décio Andriotti, SJ endossa essa ideia dizendo:

(...) Nietzsche foi autêntico em qualquer parte de seu sofrimento. A crítica favorável ou desfavorável, não o roubava à realidade amarga. Encolhiase na escravidão do quarto e passava dias remoendo uma existência que viveu no mais profundo do seu cerne. (...) soube solucionar o problema com o super-homem. ${ }^{14}$

Andriotti acentuava este aspecto da introspecção de Nietzsche, algo que já Freud havia recordado, e com um elogio - afirmando que Nietzsche era um dos que melhor se conheceu a si mesmo.

A autenticidade é outro aspecto que Andriotti sublinha no filósofo. Ser autêntico no sofrimento engrandece ainda mais a sua figura. Enfim, a descrição de Nietzsche, feita por Andriotti, dá a ideia de que o filósofo alemão possui traços estoicos bastante acentuados, lembrando a figura de uma espécie de eremita. Portou-se como alguém que abraça a solidão para melhor fruir a sua existência, ao modo daquele que deixa a confusão da cidade e sobe a montanha, para, na solidão e no silêncio, aprender “(...) de acordo com muitos dos conselhos de Zaratustra." "15 É uma solidão que implica no cultivo de si mesmo. O cultivo do silêncio, pelo afastamento das aglomerações, tem sido algo muito incentivado pelo ascetismo cristão. Por essa razão, mais uma vez o pensamento de Nietzsche é valorizado. Inclusive, de acordo com depoimentos de diversos religiosos jesuítas, ao se sentirem desolados, transtornados, recorriam comumente aos escritos de Nietzsche que funcionavam como bálsamo para a alma e o vigor para a vida. Como uma força, uma potência que brota da pura vontade

14 Andriotti, 1946, pp. 83-84

15 Ibidem, p. 86

246 | Cad. Nietzsche, Guarulhos/Porto Seguro, v.38, n.3, p. 237-258, setembro/dezembro, 2017. 
individual de se autossuperar, tal como acompanhamos nas palavras de Andriotti:

(...) a realização de todo ideal de vida, só culminaria por uma espécie de sacrifício cujo conteúdo específico não é o nobre sofrimento tradicional mas a essência da "força de poder" individualista; a significação do ato passa a ter pinceladas de Nietzsche ${ }^{16}$

e "(...) como Nietzsche levando às últimas consequências o resultado da filosofia tradicional e da 'força de poder' de Schopenhauer, criou o "super homem" "17. A chamada de atenção para o exercício da responsabilidade individual, para além de um protecionismo divino estranho e descompromissado, é o que vai movendo as diversas reações intelectuais contra o centralismo da inerrância do papa. Reações estas que têm no pensamento de autossuperação nietzschiana, ente outros, um apoio incondicional.

Há uma verdadeira ânsia por mudanças. Se é possível observálas na natureza, então por que também não ocorriam na cultura e na mentalidade humana? O Pe. Augusto Brunner, SJ, por isso, assevera:

Se na natureza se destrói toda a consciência pela evolução das espécies, por que na espiritualidade admiti-la sem demonstração, mesmo contradizendo à evidência? Já em Nietzsche tomam vulto semelhantes dúvidas. ${ }^{18}$

Se tudo respira a transformação, motivada pelas descobertas, no campo científico, realizadas por Charles Darwin, então a pergunta que se fazia na época, também no campo do pensamento e da teologia, é a de por que ainda se insiste em seguir perseguindo a ideia da rigidez e da imutabilidade, típica da estrita observância oriunda das declarações dogmáticas do Concílio Vaticano I. Dentro desse âmbito

16 Ibidem, p. 90

17 Ibidem, p. 95

18 Brunner, 1946, p. 64 
Feiler, A. F.

passam a ser repensadas as noções de progresso, história e revolução, como acompanhamos na reflexão do Pe. Antônio Thill (1898-1973):

Progresso, mas para quê? E para onde? Para todos os homens ou somente para uns privilegiados? (Disse Nietzsche que a história é um desvio da natureza para chegar a uns super-homens...). Seria então a história apenas a preparação onerosa de uma casta final de herdeiros? Onde ficariam as bênçãos da "Grande Revolução"? 19

Uma pergunta que se depreende dessa reflexão de Thill é a de quem arcaria com o ônus desta transmutação orgânica em direção ao super-homem. Por mais que nestas palavras exista, por um lado, um tom de crítica a Nietzsche, não deixa de provocar, por outro, questões existenciais.

Um outro tema que Thill ainda explora, motivado pelas provocações de Nietzsche, é o problema da cultura.

Cultura é a unidade de estilo; civilização é o caos. A primeira é original; a última é imitação que procura dar a impressão de ser criadora, fazendo reviver inúmeros fragmentos culturais. Um dêsses sintomas vê com Nietzsche no 'barulho da música verdadeiramente decadente da civilização. ${ }^{20}$

Este problema de uma decadência civilizacional, motivada pelo caos da cultura não escapa ao olhar crítico daqueles que leem Nietzsche, mesmo com suspeita. A necessidade de uma nova cultura,

(...) ideia que também já se encontra em Nietzsche, e que caracteriza a "era da barbárie pela entrada dos russos na cultura". Para ele os russos não trarão uma nova cultura, mas serão um reforço para a cultura ocidental (...) Como Nietzsche assume uma atitude negativa para com o cristianismo, embora menos violenta. Nietzsche nega a Deus porque sua transcendência desvaloriza o mundo; Deus precisa morrer para que o super-homem possa viver. $^{21}$

19 Thill, 1953, pp. 31-32

20 Ibidem, 1951, p. 06

21 Ibidem, p. 07

248 | Cad. Nietzsche, Guarulhos/Porto Seguro, v.38, n.3, p. 237-258, setembro/dezembro, 2017. 
Tal como se faz necessária uma renovação cultural, prometida com o advento do super-homem, é necessária a supressão da autoridade divina - Deus; da mesma forma também a supressão da autoridade civil - o Estado. "Nietzsche tem, quanto ao Estado, uma concepção oposta. Para ele 'o homem começa lá onde acaba

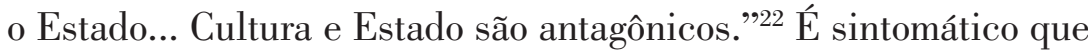
Nietzsche seja referido para se refletir sobre a maneira pela qual a autoridade, seja ela religiosa ou civil, tem se imposto; e isto num tempo num contexto em que não se questionava, apenas se obedecia.

O Pe. Luiz Müller, SJ (1894-1987), professor titular da cátedra de Filosofia do Seminário Central ${ }^{23}$ em um manual de História da Filosofia In usum scholarum (Para uso exclusivo das suas aulas), apresenta uma breve apreciação do pensamento de Nietzsche que retoma várias questões anteriormente citadas, como é o caso do problema da crítica à moral e da cultura. $O$ padre Luiz trata aqui ainda de um tema bastante delicado, aquele que veiculava o pensamento de Nietzsche ao movimento social nacionalista. Apesar de todas estas suspeitas que são levantadas ao pensamento de Nietzsche, ele não se abstém em reconhecer a importância do filósofo em ajudar a refletir sobre aspectos que urgem transformação, em que se necessita dar um passo além. É de se julgar que Pe. Luiz esteja se unindo à voz de seus demais colegas acima citados, sobre a necessidade de revisão das declarações contidas no Concílio Vaticano I, onde, novamente, Nietzsche se torna uma ferramenta importante. Transcrevemos na íntegra as palavras de Pe. Luiz:

Frederico Nietzsche (1844-1900), é pessimista, pior ainda que Schopenhauer, não tirando porém as mesmas consequências como Schopenhauer, proclama Nietzsche o culto do 'Ueber-Mensch', isto é, a raça do homem-superior (hyper-Mensch), que deve subjugar os fracos ( $c f$. o moderno nacionalismo

22 Ibidem, p. 07

23 "O principal campo de trabalho de LM foi São Leopoldo e sua atividade primordial, o magistério." (Leite, 2005, p. 125).

Cad. Nietzsche, Guarulhos/Porto Seguro, v.38, n.3, p. 237-258, setembro/dezembro, 2017. 
Feiler, A. F.

social). Por isso, diz que o cristianismo é um regresso na cultura por ter sempre ajudado aos fracos, doentes. Não o número mas sim, a qualidade dos homens é que importa.

Crítica: O que dizemos nós? É verdade, não o número, mas sim, a qualidade importa, mas. 1. Deve-se tomar qualidade em outro sentido do que Nietzsche a tomou, isto é, importa em primeiro lugar a qualidade moral e não a qualidade corporal. 2. Ainda assim não seria lícito matar os maus para se matarem só os santos, muito menos é lícito matar os santos bem que fracos, para sobreviver os robustos, atletas, ainda que diabos.

O "herói" morreu enlouquecido, fato que dispensa toda a crítica. Nem para isso estas ideias estúpidas como desastrosas ao mesmo tempo, não deixaram de acordar uma nova era, isto é, 'Zurueck zu Kant' Voltar a Kant (neo-criticismo). ${ }^{24}$

Chamo a atenção dessa nova era que o Pe. Luiz menciona em sua reflexão, que por mais estúpida e caricata que possam tomar as dimensões do pensamento de Nietzsche, há nele algo que deve ser levado a sério para se pensar a cultura.

Um desses aspectos a ser levado a sério na cultura é o que aponta o comentário do Pe. Pedro Norberto Zahnen, SJ (1897-1952), em seu manual utilizado na cadeira de Ética:

Spiritu sententiarum Nietzsche qui per suum stilum fascinantem innumerorum lectorum admirationem et enthusiasmum provocavit, sed simul inserivit despectu et odium religionis christianae et docuit moralem independentem ab hac religione, immo moralem oppositam, ut e. g. diceret humilitatem et abnegationem vitia, superbiam et egoismum virtutes. ${ }^{25}$

De acordo com Pe. Zahnen, Nietzsche chama a atenção a um aspecto fundamental na cultura: a sua dimensão estética que

24. Müller, 1934, p. 104

25 "O Espírito das sentenças de Nietzsche, que por seu estilo fascinante tem provocado admiração e entusiasmo em numerosos leitores; mas ao mesmo tempo tem introduzido desprezo e ódio à religião cristã, tem ensinado a independência moral desta religião, muito ao contrário à moral oposta, de modo que enquanto aquela afirmou a humildade e a abnegação, esta afirmou a soberba e o egoísmo". (Zahnen, 1941, p. 315).

250 | Cad. Nietzsche, Guarulhos/Porto Seguro, v.38, n.3, p. 237-258, setembro/dezembro, 2017. 
ele aponta em seu próprio estilo de escrita. Traz Zahnen, em sua reflexão, um ponto fundamental das críticas que Nietzsche dirige à cultura, de maneira particular ao Cristianismo: a moral. No entanto, se aprofundamos este aspecto da moral percebemos que Zahnen apresenta uma crítica a Nietzsche sob o aspecto de ter acentuado uma moral sedimentada na soberba e no egoísmo contra a moral cristã da humildade e da abnegação, inclusive sublinha que Nietzsche introduziu o desprezo e o ódio à religião. Um outro aspecto da cultura que Zahnen aponta em suas observações sobre Nietzsche é a questão da política como acompanhamos em suas palavras:

Quoad politicam Nietzsche proedicit apparitum esse 'superhominem', qui dominetur toti 'gregi' ceterorum et imponat omnibus nececitatem suae voluntatis, - qui tendat in augmentum suae potentiae independenter ab omni morali et jure si quis satus moderatur his ideiis afficitur, quid erit cum idea et praxi sui regiminis? ${ }^{26}$

Com relação à dimensão política, Zahnen sustenta a figura do Super-Homem; aquele que, com sua superioridade, submete ao seu jogo a massa do rebanho. Aqui chama a atenção a leitura que Zahnen faz: ele simplesmente substitui o foco de opressão do rebanho que, no caso de Nietzsche, é o Cristianismo para o Super-Homem. A vontade de potência deste último é incrementada às custas do rebanho. Esta leitura dá margem para aquela crítica que há muito foi tributada a Nietzsche, a de que sua filosofia estivesse incrementando um tipo de visão antropológica eugênica, base de uma política social nacionalista. Este tipo de leitura da filosofia de Nietzsche foi talvez um dos mais perniciosos para suas pesquisas futuras, o que o relegou durante muito tempo numa posição caricatural. Disso resultaram inúmeros ditos e expressões que, em diversos casos, se afastaram do sentido

26 “Até que ponto Nietzsche apresentou a política - é evidente que o 'super-homem', que aliás dominou todo o 'rebanho' e impôs a sua vontade sobre todas as necessidades - que se inclina para o aumento de sua potência, independente de toda a moral e justiça. Se alguma posição é moderada por ideias que causam impressão, porque era com a ideia e a prática de seu governo?” (Ibidem).

Cad. Nietzsche, Guarulhos/Porto Seguro, v.38, n.3, p. 237-258, setembro/dezembro, 2017. | 251 
Feiler, A. F.

de seus escritos, repercutindo em retrocesso quanto às pesquisas acerca do pensamento de Nietzsche.

\section{A recepção de Nietzsche em outros textos, ditos e expressões}

Diversos textos como os do jornalista, político e teólogo Plínio Salgado, representante do movimento integralista, figurava entre o acervo da biblioteca, portanto acessível a todos de maneira livre. Este autor, conhecido por sua marca anti-comunista, traz em um texto seu uma referência bastante importante sobre o perigo de autores como Marx e Nietzsche.

O Comunismo é a expressão agressiva, dogmática e niilista do materialismo.

Origens filosóficas do Comunismo: "É a filosofia da ação que encontramos em Nietzsche e Marx". Inspirados ambos em Hegel: O materialismo de Nietzsche, através de Max Stirner, encontra-se no idealismo de Hegel, da mesma maneira, como através de Feuerbach, Marx se radica na mesma origem filosófica. ${ }^{27}$

Chama a atenção, por este excerto que os escritos de Nietzsche são temidos por estarem associados ao Comunismo. Principalmente pela dimensão de práxis que inspiram. Nesta mesma linha, Pe. Leonel Franca, SJ (1893-1948) ${ }^{28}$ apresenta o pensamento de Nietzsche e o de Marx ligados a um terrenismo, na exaltação seja do herói individualista, o super-homem, seja do coletivismo proletário.

O próprio Nietzsche, que na magia de um estilo incandescente, fulmina os "coveiros da vida" e entoa cantos de vitória à glória do superhomem

27 Salgado, 1957, p. 81.

28 Pe. Leonel Franca, SJ, nascido em São Gabriel/RS em 1893, foi um jesuíta de destaque, inclusive foi o fundador da PUC/Rio.

252 | Cad. Nietzsche, Guarulhos/Porto Seguro, v.38, n.3, p. 237-258, setembro/dezembro, 2017. 
emancipado, descreve-nos por vezes, num trágico impressionante, o "nada infinito" do Sem-Deus. ${ }^{29}$

Além disso, o Pe. Franca acentua, no pensamento de Nietzsche, a sua dimensão orgânica através da corrente de pensamento denominada vitalismo: “(....) é Nietzsche, quem desenvolve o vitalismo de modo inteiramente consequente e lógico" ${ }^{30} \mathrm{O}$ vitalismo, tal como acentuado pelo Pe. Franca, destaca a dimensão da práxis, fundamental para pensar a ética em Nietzsche, uma ética da vida, da ação, e da prática.

Curiosamente, se por um lado essa mesma práxis é questionada por conduzir ao comunismo, por outro, é valorizada por atender a uma dimensão humana efetiva, a vida, como lemos nas palavras de Pe. Orlando Vilela: (1914-1989)

(...) o cristão deve ser um homem deste mundo, como qualquer outro, e mesmo mais do que qualquer outro. Sim, mais do que qualquer outro, ele deve ser "o sentido da terra", para usar de uma expressão cara a Nietzsche e também a Teilhard de Chardin." 31

Um curioso paralelo, ou convergência de atenção, pode ser estabelecido entre a recepção de Nietzsche e a recepção de Teilhard de Chardin. Para a época em que foi escrito este comentário parece bastante curioso, pois foi um período sacudido por inúmeras transformações oriundas do Concílio Vaticano II, um órgão de autoridade máxima na Teologia da Igreja Católica. Assim, dizer que o ser humano é o sentido da terra é o mesmo que endossar um aspecto muito importante presente nos decretos do Vaticano II, que é o sentido de encarnação. Ressalta-se a dimensão humana de Jesus, como aquele que fruiu ao máximo a vida, a valorizou e a afirmou. É curioso, igualmente, o fato de Nietzsche ser colocado ao lado de

29 Franca, 1941, p. 144

30 Franca, 1921, p. 244

31 Vilela, 1968, p. 35. 
Feiler, A. F.

Teilhand de Chardin (1881-1955), um paleontólogo jesuíta que, por suas ideias avançadas a respeito de uma releitura do evolucionismo de Darwin, sintetizadas principalmente em seu Fenômeno Humano foi, durante muitos anos, exilado na China a fim de não divulgar tais ideias. Inclusive, dos anos de 1925 a 1962, seus livros estiveram inclusos no Index. Contudo, chama a atenção que a Igreja venha a reconhecer no pensamento deste religioso elementos que não estão em contradição a sua doutrina, mas ajudam a esclarecê-la. Segundo diversos testemunhos, algo talvez parecido tenha ocorrido, porém, muito tempo após o dito reconhecimento do pensamento de Chardin, com o pensamento de Nietzsche. Toda a crítica que Nietzsche faz ao Cristianismo, como sendo um Platonismo para o povo, em grande parte contribuiu no processo que veio a culminar com o Concílio Vaticano II.

Nesta altura de nossa pesquisa gostaria de ainda ilustrar, ainda, um aspecto que até os dias atuais é motivo de comentários entre vários jesuítas. Conta-se que um dos padres, o alemão Pe. Antonius Kordt, SJ, que fora, durante quase toda a sua vida, bibliotecário nesta instituição, em seu leito de morte, que se deu em 1970, entre delírios tenha feito afirmações como esta: "Nietzsche hat recht - es gibt kein Gott"32. Assim, amado ou odiado, compreendido ou malentendido, o pensamento de Nietzsche certamente marcou todo um longo período histórico que dominou a existência do Seminário Central Nossa Senhora da Conceição.

\section{Considerações finais}

Pelo nosso itinerário, pudemos ter uma ideia de que a recepção de Nietzsche, no Seminário Central Nossa Senhora da Conceição, contrariamente ao que se esperava, não foi de todo caricata e depreciativa. Talvez Nietzsche tenha sido mais utilizado como

32 "Nietzsche tinha razão - Deus não existe".

254 | Cad. Nietzsche, Guarulhos/Porto Seguro, v.38, n.3, p. 237-258, setembro/dezembro, 2017. 
ferramenta para a crítica sobre aspectos da doutrina resultante que se respirava com as conclusões do Concílio Vaticano I. O pensamento de Nietzsche contribuiu para se repensar um modelo institucional que até então vigorou, principalmente no que diz respeito à dimensão da afirmação da infalibilidade papal. As provocações de Nietzsche com respeito à verdade, à cultura e ao Cristianismo marcaram de maneira significativa o quotidiano acadêmico do Seminário Central; não apenas pela maneira bela como Nietzsche se expressava no idioma alemão, mas também pelo conteúdo filosófico que expressava.

Tanto entre os autores que influenciaram a produção sobre Nietzsche quanto aos que o recepcionaram, seja em seus manuais de aula, seja outros escritos, ditos e expressões, é sintomático o impacto da concepção de super-homem. Esta tem sido lida pelo viés da eugenia, o que se traduz como um tipo de pensamento associado ao Nazismo. Por essa razão, foi tido como um pensamento preocupante, desconcertante, e, por isso, instigante. Apesar das críticas que se depreendem dos manuais de aula escritos no Seminário Central sobre o pensamento do filósofo, não se pode negar o aspecto do fascínio e da crítica, assim como o de uma nova era que o pensamento aponta, tal como o Pe. Müller se expressa em termos de um neo-criticismo. É interessante que se vê, para além de uma crítica, em muitos aspectos deletéria, uma chamada de atenção para um futuro de mudanças, diante do qual não se pode acomodar. Este fascínio é, também, sublinhado pelo Pe. Zahnen com respeito à essência das sentenças nietzschianas, principalmente pela sua beleza estilística e pelo entusiasmo que convoca à ação.

Os professores do Seminário Central compreenderam muito bem o quanto o pensamento de Nietzsche valoriza a marca das diferenças contra uma uniformidade estática e infrutífera. Por essa razão, perceberam que Nietzsche, para além de apresentar uma crítica à vida comunitária e social, é contra a massificação que pode ser demandada por um determinado tipo de Comunitarismo, a fim de 
que o super-homem, o espírito livre, munido da força, que é vontade de potência, pudesse emergir. No entanto, este super-homem, como observou o Pe. Steffen, não é de todo ruim, pois por ele se é capaz de ultrapassar o estado de submissão e a renúncia à capacidade de agir como propulsores da decadência cultural.

Os aspectos de irregularidade que se depreendem tanto da natureza como da espiritualidade, contra a noção platônica de ordem, atestam aquela noção de instabilidade que inspirou ao Pe. Augusto Brunner em buscar na filosofia de Nietzsche pistas para se pensar toda esta situação de mudanças, dúvidas e incertezas. Toda esta sorte de dúvidas e incertezas têm influenciado decisivamente a maneira de se encarar temas como a religião, a moral e a cultura. Neste sentido, o pensamento de Nietzsche cumpriu um papel importante.

Nietzsche's reception from the Library Index of the Central Seminary of São Leopoldo/RS

Abstract: The Index of library of Central Seminary of Imaculate Conception in São Leopoldo, at Rio Grande do Sul kept a big part of philosophical work that, in the years before the Vatican II Concilian, it was greatly in suspicious. Within it shows up all the Nietzsche's work, which this text deals with. However paradoxical that it can be, Nietzsche, despite controversial manner whereby treats about themes as the culture, the moral, the Christianity, Nietzsche met, in the Central Seminary many readers. These, attracted by the beauty of its stile and by the impetuous manner whereby with witch he faced the problems of his time, took the Nietzsche's thought, largely, seriously. It can be infer the hypothesis of that Nietzsche's thought reception in the Central Seminary setting up, somehow, as tool to think the future destiny of institutional Church.

Keywords: Nietzsche - Reception - Index - Christianity. 
A recepção de Nietzsche a partir do Index da biblioteca do ...

\section{Bibliografia}

ANDRIOTTI, D. Solidão, Destino, Imanência. In: $O$ Seminário, Porto Alegre, n. 4, pp. 79-97, 1946.

BOHNEN, A; ULLMANN, R. A atividade dos Jesuitas de São Leopoldo 1844-1989. São Leopoldo: Editora Unisinos, 1989.

BRUNNER, A. Os problemas básicos da filosofia. São Paulo: Companhia Editora Nacional, 1946.

CATHREIN, V. Philosophia Moralis. In usum Scholarum. São Leopoldo, 1907.

FRANCA. L. Noções de História da Filosofia. Rio de Janeiro: Livraria Drumond, 1921. 1941.

. A crise do mundo moderno. Rio de Janeiro: Livraria José Olympio Editora,

GEMMEL, J. Ethica Philosophica. Valkenburg, 1931.

LEITE, L. O. Jesuítas no sul do Brasil. São Leopoldo: Editora Unisinos, 2005.

MÜLLER, L. História da Filosofia. (Manual de Aula). São Leopoldo, 1934.

NIETZSCHE, F. W. Also sprach Zarathustra. Leipzig: C.G. Naumann, 1899.

SALGADO, P. O homem integral. Rio de Janeiro: Livraria Clássica Brasileira S/A, 1957.

STEFFEN, H. A. Kierkegaard e a religião. Porto Alegre: Estudos, 1958.

THILL, A. O desaparecimento da cultura ocidental segundo Oswaldo Spengler. In: Formação. Revista Brasileira de Educação, Rio de Janeiro, n. 150, pp. 04-15, 1951.

O cristão no fim dos tempos modernos. Um novo humanismo? In: Formação. Revista Brasileira de Educação, Rio de Janeiro, n. 179, pp. 29-38, junho de 1953.

TREVISAN, A. A propósito da dor. In: O Seminário, Porto Alegre, n. 4, 1946.

Cad. Nietzsche, Guarulhos/Porto Seguro, v.38, n.3, p. 237-258, setembro/dezembro, 2017. | 257 
Feiler, A. F.

VILELA, O. A pessoa humana no mistério do mundo. Petrópolis: Vozes, 1968.

ZAHNEN, N. Ethica. Liber Secundus. São Leopoldo: Seminário Central e Colégio Máximo (Ad usum nostrorum), 1941.

Artigo recebido para publicação em 25/01/2017 Artigo aceito para publicação em 31/03/2017 